\title{
Roberto Bolaño e a inflexão do marxismo na crítica sobre a literatura da América Latina do séc. XXI
}

Juan Castro Chacon ${ }^{1}$

En Bolaño no se trata de distinguir entre verdad y ficción. Ha creado un espacio en el que

las cosas son simultáneamente normales e insólitas: "la vida no sólo es vulgar sino también inexplicable", "lamentable pero vulgar", "apacible pero también extraña". Juan Antonio Masoliver Ródenas, Roberto Bolaño: la escritura como tauromaquia, 2006.

Resumo: Esta pesquisa tenta estabelecer um diálogo entre a crítica literária do séc. XXI e o marxismo, por meio da obra crítica ensaística de Roberto Bolaño Entre paréntesis (2011). Nesta publicação, Bolaño discute algumas das vozes narrativas do séc. XX, no viés crítico geopolítico em que se movimentam, canonizadas ou não, definindo, inflexivamente, um passo ao estudo da narrativa não-cânone. Nesse sentido, acredita-se que Bolaño, ao fundamentar a obra contemporânea, na descontinuidade (GONZÁLEZ, 2010), cria uma inflexão crítica que se desprende do marxismo dialético, na aliança entre o real e a ficção, numa narração latino-americana de finais do século passado.

Palavras-chave: Roberto Bolaño. Inflexão. Marxismo. Crítica literária.

Abstract: This research aims to establish a dialogue between XXI century criticism and Marxism, by Roberto Bolaño's critic work Entre paréntesis (2011). In this work, Bolaño analyses some narrative voices from XX century by critical geopolitics bias where they go around, canonized or not, defining inflexible, a step towards to non-canonized narrative. In this regard, it is believed that Bolaño, by supporting a contemporary work in discontinuity (GONZÁLEZ, 2010), elaborates a critical inflection. This inflection is separated of dialectic Marxism, in alliance between real and fiction, in Latin America narrative from the end endings of last century.

Keywords: Roberto Bolaño. Inflection. Marxism. Literary criticism.

Resumen: Esta investigación intenta elaborar un diálogo entre la crítica literaria del siglo XXI con el marxismo, a través del ensayo crítico de Roberto Bolaño Entre paréntesis (2011). En esta publicación, Bolaño discute algunas voces narrativas del siglo XX, con el enfoque crítico geopolítica en que se mueven, canonizadas o no, dando, inflexivamente, un paso a la narrativa no canon. En este sentido, se piensa que Bolaño, al fundar la obra contemporánea, en la discontinuidad (GONZÁLEZ, 2010), elabora una inflexión crítica que se suelta del marxismo dialéctico, derivada de la alianza entre lo real y la ficción, en una narración latinoamericana de fin del siglo pasado.

\footnotetext{
${ }^{1}$ Doutorando do Programa de Pós-Graduação em Letras e Linguística da Faculdade de Letras da Universidade Federal de Goiás. Mestre em Estudos Literários pelo mesmo Programa.
} 
Palabras clave: Roberto Bolaño. Inflexión. Marxismo. Crítica literaria.

\section{Considerações iniciais:}

O já iniciado séc. XXI está marcado pela virtualidade, pela globalização geopolítica e pelas reorganizações sociais, no que cerne às temáticas "pósmodernas"2 ou, simplesmente, discussões com o prefixo pós. Estas mudanças socioculturais afetam (in)diretamente o sistema-mundo, na medida em que implementam renovadas discussões às trajetórias ditas conservadoras ou tradicionais. No sistema literário não é diferente a problematização. Pois, a literatura como polissistema (EVEN-ZOHAR, 2013) é uma (re)construção baseada na tendência narrativa que ela mesma estrutura, sofrendo, também, outras estruturações como consequência, ou seja, o campo da literatura é um polissistema "estruturante e estruturado" (BOURDIEU, 2015). Nessa perspectiva, a literatura é tão dinâmica quanto a própria língua, mas se encontra passiva a certas regras de funcionamento, no caso, do eixo que a direciona e faz escolhas por ela: o cânone. Assim, o campo literário (BOURDIEU, 2010), embora autônomo para ser cambiante e dinâmico, está interligado a vários outros sistemas dos quais se alimentará, em condição das regras produzidas desde seu interior e exterior, relacionando-se como um todo para poder produzir sua narrativa, ratificando seu próprio espaço e tempo.

Adere-se, assim, a tendências/estilos crescentes, enquanto vai deixando outros, de acordo com seu centro de recepção e canonização, nomeados paradigmas literários pelas singularidades narrativas que apresentam. A recepção e a fortuna crítica as considerarão clássicas universais, de acordo com o julgamento dos seus respectivos ambientes (inter)nacionais.

Consequentemente, as produções literárias estão regidas por teorias que apoiam e (re)criam esses paradigmas, já que o movimento da literatura acompanha a fixidez da ciência em seu momento, sobre certos aspectos teórico-

\footnotetext{
2 Não é pretensão desta pesquisa entrar em detalhes para explicar que a polêmica nomenclatura "pós-moderna" ou "pós-modernidade" vai ou não de acordo com a linearidade temporal, nem que ela possa explicar por si só todos os câmbios epistemológicos ou fenômenos socioculturais no séc. XXI.
} 
políticos, por uma condição própria do paradigma (re)criado. Como exemplos estão a experiência da literatura da "arte pela arte", desde seu ponto aristotélico, ou a crítica literária baseada nas ideologias, como a marxista.

Nesse sentido, o pensamento desenvolvido por Karl Marx, no séc. XIX posteriormente classificado como marxismo - foi/é uma das maiores referências para os estudos literários posteriores à sua data de publicação, em $1867^{3}$. Diferentes áreas de ciência de finais de séc. XIX e inícios do séc. XX dedicaramse a tomar o pensamento marxista para suas bases epistemológicas. A literatura não foi a exceção e também se desenvolveram teorias e críticas em conteúdos direcionados para o pensamento de Marx. É, assim, que se produzem estudos sobre a literatura desde uma abordagem ideológica de determinado paradigma espaço-temporal, como Marxismo e filosofia da linguagem de Mikhail Bakhtin (1995), Marxismo e teoria da literatura de György Lukács (2010), Magia e técnica, arte e política de Walter Benjamin (2012), entre outros.

Estas obras citadas juntam a arte literária a problemáticas apresentadas sob um aspecto ideológico, o marxismo, considerando que em toda obra/produção literária existe uma realidade. Como menciona Bakhtin "um produto ideológico faz parte de uma realidade (natural ou social) como todo corpo físico, instrumento de produção ou produto de consumo" (1995, p. 31). Embora a explicação de Bakhtin assuma mais adiante a exterioridade da realidade, seus estudos fornecem um primeiro e fundamental consenso sobre a arte da linguagem e das ideologias, com suas aproximações ao marxismo ou, em todo caso, bifurcações ou rupturas.

Nessa questão, não se pode omitir o cânone - sistema que rege uma área de conhecimento desde seu eixo - e a sua manipulação na conservação do status quo literário ou, em todo caso, manipulação para introduzir uma tendência/estilo renovado ${ }^{4}$. Sem embargo, o polissistema literário não só contesta uma realidade, mas as realidades, destacando que, como polissistema, o movimento ideológico espaço-temporal propõe renovadas formas artísticas.

3 Sobre os 150 anos da obra, embora publicada em 1867. Disponível em: <https://revistacult.uol.com.br/home/o-capital-de-karl-marx-150-anos-depois>. Acesso em: 23 jul. 2018.

${ }^{4}$ Um exemplo histórico visível é a criação das vanguardas, do francês avant-garde, sobretudo nas artes. 
Sendo assim, torna-se preciso rever as críticas da literatura por um escopo contemporâneo e fora do centro europeu, sobretudo pelas narrativas que os inícios do séc. XXI construíram na América Latina, inclusive, legados do séc. XX. Assim, esta pesquisa propõe a leitura da obra ensaística de um dos autores latino-americanos contemporâneos mais reconhecidos pela crítica mundial, 0 escritor Roberto Bolaño mediante a sua coletânea crítica póstuma Entre paréntesis (2011).

A dinâmica narrativa deste escritor faz com que sua produção literária em geral seja marcada por variedades linguísticas, políticas, artísticas e socioculturais latino-americanas. Sua infância, adolescência e juventude transitaram desde o Chile - país de origem - até o México, inclusive após fugir da ditadura do general Pinochet, percorrendo, no trajeto, diversos países latinoamericanos. Anos mais tarde, migrou para a Catalunha, na Espanha, lugar em que radicou até seu falecimento, em 15 de julho de 2003, aos cinquenta anos.

Nesse viés, Roberto Bolaño é catalogado como o melhor escritor da sua geração (SONTAG in HERRALDE, 2005; MANZONI, 2002) - uma geração de permuta de séculos - e amplamente estudado e comentado, inclusive no mundo virtual, lugar característico da mudança secular. É assim que se leem comentários variados sobre a sua obra, produção que goza de fortuna crítica e recepção positivas, nas que se destacam até pareceres do escritor sobre a literatura, por exemplo o de Ernesto Santana Zaldívar, sobre o ofício de Bolaño na literatura:

\begin{abstract}
Bolaño no escribió su narrativa para demostrar una teoría literaria, para comenzar o seguir una escuela y ni siquiera para imponer la buena literatura por encima de las montañas de libros comerciales que inundan el mundo. Escribió para sacarse de adentro esos personajes y ese mundo tan vívidos, sin importarle el destino de sus libros, porque, como había confesado ya, "solo deseo recuperar la disponibilidad cotidiana de mi escritura, líneas capaces de cogerme del pelo y levantarme cuando mi cuerpo ya no quiera aguantar más"s.
\end{abstract}

Numa primeira perspectiva, a descrição de Santana Zaldívar revela um escritor crítico, em primeiro lugar, sobre o olhar da vivência, da experiência com a literatura sem teoria literária, nem para uma boa literatura. No entanto, pelas

5 Disponível em <https://www.cubanet.org/articulos/roberto-bolano-la-unanimidad-me-jodemuchisimo/>. Acesso em 05 ago 2018. 
últimas linhas se observa o desespero do escritor, sabendo a finitude que expressa o oficio de escrever, a literatura do corpo vivo.

Nesse sentido, a crítica de Bolaño talvez aponte para um espaço literário em especial, América Latina, e uma atemporalidade, a literatura vivenciada de entre séculos XX-XXI, para remarcar seu discurso. "¿Se puede tener nostalgia por la tierra en donde uno estuvo a punto de morir? [...]. Para el escritor de verdad su única patria es su biblioteca" (2011, p. 43), diria Bolaño.

Por tal motivo, o objetivo da pesquisa é tentar estabelecer um diálogo com a crítica literária baseada no marxismo para poder observar como a obra de Bolaño cria uma inflexão crítica com aquela. Para alcançar esse objetivo e justificar a hipótese, o trabalho terá como método o uso e leitura de referências escritas, dirigindo o foco para o corpus do livro Entre parêntesis. Assim, a pesquisa está dividida em três partes: i) Literatura, ideologia e cânone, nas quais se expõem algumas características imprescindíveis da literatura na sua função como polissistema; ii) Marxismo e latinismo, em que se provoca a discussão com o marxismo literário dentro do contexto latino-americano e um possível latinismo; e iii) Roberto Bolaño e a literatura das Américas, cuja reflexão leva a pensar sobre o destino da literatura produzida no continente americano para um refúgio narrativo-crítico particular.

\section{Literatura, ideologia e cânone}

Discutir o que é literatura num mundo tão globalizado e diversificado ao mesmo tempo, como está atualmente o sistema-mundo, seria uma aposta superficial ou extensiva demais, se não se ressalta toda a estrutura que se desenvolve ou se liga nela. Por outro lado, há certas premissas que podem fazer com que a literatura - ou campo de produção e distinção, como citaria Bourdieu (2010, 2015) - possa ser mais evidentemente explicada, seguindo o padrão do seu movimento. No caso, tomar a literatura com o conceito que Bourdieu atribui aos espaços sociais de relações objetivas (BORDIEU, 2010, p. 64), o campo literário está relacionado, em primeiro estágio, com a intelectualidade (BORDIEU, 2010, p. 65). Nesta concepção, o campo da literatura, como conceito geral, 
supõe estratificações de poder na sua relação interior/exterior, uma verticalidade particular nas suas formas interdependentes, que de alguma maneira dificultaria um foco de discussão e explicação mais específico.

Assim, cita-se, em primeiro lugar, a literatura já não como campo ${ }^{6}$, mas como polissistema, na sua complexa dinamicidade em que se mobiliza, em relação de expansão mais acentuada ao horizontal. Logo, um polissistema é:

\begin{abstract}
Um sistema múltiplo, um sistema de vários sistemas com intersecções e sobreposições mútuas, que usa diferentes opções concorrentes, mas que funciona como um todo estruturado, cujos membros são interdependentes (EVEN-ZOHAR, 2013, p. 3).
\end{abstract}

Em primeiro lugar, o professor Even-Zohar observa a composição do polissistema, mas agrega também que:

\begin{abstract}
Visto neste contexto, o termo "polissistema" é mais que uma convenção terminológica. Seu propósito é tornar explícita uma concepção do sistema como algo dinâmico e heterogêneo, oposta ao enfoque sincronístico. Desse modo, enfatiza a multiplicidade de interseções e, a partir disso, a maior complexidade na estruturação que isso implica. Salienta ainda que, para que um sistema funcione, não é necessário postular sua uniformidade. Uma vez reconhecida a natureza histórica de um sistema (um grande mérito na hora de construir modelos mais próximos ao "mundo real"), impede-se a transformação dos objetos históricos em seres de acontecimentos ahistóricos sem coesão entre si (EVEN-ZOHAR, 2013, p. 3-4).
\end{abstract}

Dessa maneira, a literatura, campo literário ou literatura como polissistema afinca sua estrutura na ligação com as partes que a conformam, uma rede múltipla que se junta e se separa em várias direções e seções, e que, segundo afirma Even-Zohar, o polissistema literário é um total interdependente ligado proximamente à história real de um determinado sistema espacial.

Partindo para a obra Entre paréntesis de Roberto Bolaño, a literatura, para ele, é vista como a pátria do escritor, o único que poderá levar o escritor sempre, na sua biblioteca ou na sua memória (BOLAÑO, 2004, p. 43).

Seguindo o raciocínio da literatura como pátria do escritor, o que haveria de se supor sobre a ideologia como uma forma interseccional - e

\footnotetext{
6 Pierre Bourdieu, ao mencionar a literatura como campo, ajunta-lhe, em verticalidade, diversos fatores aglutinadores/modificadores que se encontram na sua estrutura como o cânone, a distinção da obra, o capital cultural do leitor, a recepção, o repertório, a distribuição, a edição etc.
} 
interdependente - dentro da literatura? Aliás, a literatura como polissistema abraçaria a situação ideológica do espaço-tempo como situação real absoluta?

Para esclarecer o papel da ideologia na literatura, cita-se um exemplo: é pouco provável que uma ideia/estética literária renascentista tenha sucesso no séc. XXI, dada a virtualização e as discussões originadas por elementos deste século. Haveria desconexões significativas se colocadas em comparação, a menos que se retomassem diversos fatores que priorizem uma volta a um paradigma anterior ${ }^{7}$ - saudosismo, folclore, conservadorismo, tradição, tendência retrô/vintage, que não seria de todo impensável.

Por esse viés, entender a literatura como um sistema complexo não é somente observar o espaço-tempo da sua estruturação, mas também olhar para os contextos socioculturais que se aproximam e se distanciam dela, a partir da relação espaço-temporal e da sua interdependência simbólica. Assim, a ideologia estará presente nos contextos literários por essa analogia. No caso, para o culturalista Raymond Willians, no seu livro Marxismo e literatura (1979), toda produção literária possui uma estrutura de sentimento, fundamento que correlaciona uma narrativa com seu tempo-espaço ideológico, um materialismo cultural aderido a ela. Essa reflexão, por sua vez, é a perspectiva de Willians desde uma análise marxista. Porém, como se pode ter um conceito adequado da ideologia nesta perspectiva cultural?

O professor Slavoj Žižek, na sua recompilação Um mapa da ideologia (2013), tenta mostrar o conceito que ainda se tem da ideologia como uma forma ultrapassada de "relação da representação entre o pensamento e realidade" (ŽIŽEK, 2013, p. 9). Igualmente, ele agrega que:

\footnotetext{
"Ideologia" pode designar qualquer coisa, desde uma atitude contemplativa que desconhece sua dependência em relação à realidade social, até um conjunto de crenças voltado para a ação; desde o meio essencial em que os indivíduos vivenciam suas relações com uma estrutura social até as ideias falsas que legitimam um poder político dominante. Ela parece surgir exatamente quando tentamos evitá-la e deixa de aparecer onde claramente se esperaria que existisse (ŽlŽEK, 2013, p. 9).
}

7 É muito comum que outras expressões artísticas, como a música e a escultura, por exemplo, tenham fortes laços com paradigmas anteriores, perante os concertos de música clássica ou arquitetura vintage em casas e mansões. 
Dessa forma, a ligação entre ideologia e literatura formaria um sistema que descaracteriza funções estáticas - como a literatura como arte pura, para ela mesma, com autonomia plástica irredutível. Por outro lado, essa interligação permeia o polissistema literário dentro de um espaço-tempo marcado, além de se circunscrever em função do poder de um sistema que se estrutura a partir das suas relações internas, para o exterior: o cânone. De alguma maneira, o cânone trabalha em favor/oposição à literatura como força do reflexo (LUKÁCS, 2010), a literatura como manifestação que (re)conhece uma realidade exterior.

O cânone literário seria, então, uma forma conjunta e interdependente institucionalizada ${ }^{8}$, que adquire força estruturante através das regras/juízos de valor sobre determinada expressão artística escrita, e que pode ser estruturado de acordo, também, com as próprias regras que ele mesmo estrutura. A esta reflexão conceitual, agrega-se a ideia de gosto (BOURDIEU, 2015), porque o cânone, como instituição de juízos de valor estruturantes de uma produção literária, fundamenta-se no critério do gosto pelo belo - ideológico - como caráter primordial de escolhas no polissistema literário. E vale lembrar que este é um ponto fundamental para a crítica literária de base marxista, ao analisar autores canonizados e suas respectivas índoles nacionais.

Nesse quesito, a crítica de Entre paréntesis rompe o lugar canônico de diversos sistemas literários, como no caso do mundo da poesia chilena, que ainda vive no passado de glória (BOLAÑO, 2004, p. 86-88) ou da Academia Brasileira de Letras rotulando de bruxaria a obra de Paulo Coelho e de insensatas as declarações exageradas de Nélida Piñon sobre o carioca (BOLAÑO, 2004, p. 103. Por conseguinte, o cânone, que parecia ser uma exigência fundamental em toda formação literária espaço-temporal, perderia espaço na crítica marxista ao revelar, esta, a sua posição de exclusivista, com tendência ao consagrado. Nesse caso, o cânone é (re)criador e (re)conhecedor da erudição, ou aquilo que julga o reconhecimento da alta cultura, legitima consequentemente, e em luta de classes - uma baixa cultura ou cultura espúria.

\footnotetext{
8 Vocábulo originado no interior da liturgia papal, há mais de quinze séculos atrás. Um conceito trabalhado nesta pesquisa, a partir da releitura do E-Dicionário de Termos Literários de Carlos Ceia. Disponível em: <http://edtl.fcsh.unl.pt/encyclopedia/canone/>. Acesso em: 25 jul. 2018.
} 


\section{Marxismo e latinismo}

O marxismo foi/é frequentemente usado - ao longo da sua existência para explicar questões sociais no sistema-mundo, muito mais no âmbito econômico do que em outras problemáticas das ciências humanas. É uma ideologia construída por Karl Marx e F. Engels a partir de uma análise da trajetória da revolução industrial na Europa que dividirá as castas sociais e formará diversos tipos de dicotomias, sendo a mais conhecida a divisão tensa - e constante - entre ricos (burgueses) e pobres (operários) ${ }^{9}$. Relacionado à produção e ao valor de uma mercadoria, o marxismo especifica as partes históricas que envolvem o processo de produção, em especial, a força do trabalho: o homem (MARX, 2008).

Assim se originaria o marxismo, sendo que algumas análises posteriores marcaram conceitos que o relacionam a teorias específicas, como o conhecido materialismo histórico. Esta reflexão teórica toma o trajeto histórico das relações humanas mais amplas - sociais e econômicas - como algo concreto, ou seja, algo que se pode explicar desde suas relações materiais com a história, em situações opostas $^{10}$. Daí a derivação dialética do materialismo histórico.

Nessa condição, estudiosos, pesquisadores e livre pensadores de diversas áreas do conhecimento abordaram a teoria marxista como sistema metodológico para suas discussões. Sigmund Freud foi um dos mais conhecidos em se adentrar à psicologia por essa abordagem teórico-metodológica, seguido pelo seu discípulo Jaques Lacan. Já para o lado dos estudos literários, um dos pioneiros que assume o marxismo para a análise da literatura foi G. Lukács, como supracitado, por meio da discussão sobre teoria do reflexo e outras perspectivas dialéticas (LUKÁCS, 2010). Além dele, Walter Benjamin também observa algumas questões do materialismo histórico na arte literária, ao dizer que, ao narrar ou ouvir uma história, estamos na "faculdade de intercambiar experiências" (BENJAMIN, 2012, p. 213). Também, outros autores abordam a

\footnotetext{
${ }^{9}$ Não é pretensão da pesquisa aprofundar num tema que está sumamente divulgado e explicado, sobretudo no que se refere à luta de classes e outros desígnios nominais e sociais, como a maisvalia, a burguesia, monarquia ou os feudos, por exemplo.

10 Para uma melhor compreensão e maior leitura do tema, o texto de August Thalheimer. Disponível em: <https://www.marxists.org/portugues/thalheimer/1928/materialismo/Introducao-aoMaterialismo-Dialetico.pdf>. Acesso em: 20 jul. 2018.
} 
análise sobre a crítica e a teoria literária sob esse viés - o marxismo/materialismo histórico -, todavia com uma perspectiva mais crítica, inclusive contra o próprio pensamento literário influenciado pelo marxismo, destacando-se aqui as obras de Theodor Adorno (2012) e de Erich Auerbach (2015).

Consequentemente, assim como discute o materialismo histórico sobre 0 movimento da realidade como algo concreto e em relação oposta, as problemáticas e propostas filosóficas também se (re)contextualizam face às posições ideológicas em voga. É por isso que as contribuições de Adorno e de Auerbach, ainda que justificadas as teorias literárias baseadas no materialismo histórico dialético, também não são em sentido único ao reflexo do social. $E$ perante a expressão narrativa de finais do séc. XIX, Auerbach (2015, p. 371), ao fazer uma leitura da obra de Proust, aponta que a coletividade, como condição objetiva, dialoga estreitamente com a individualidade, como condição subjetiva, pelo contato das leituras entre as elites e as massas.

Ao observar estas últimas características, a reflexão deste trabalho voltase para a possibilidade da crítica literária contemporânea considerar não uma ideologia em si, mas um processo de experiências que ofereça como produto final uma narrativa peculiar, para além de uma ideologia específica. No caso, a crítica literária afincada na literatura latino-americana de finais do séc. $X X$, como produção determinada pela sua própria estética.

Por esse viés, esta pesquisa usa o nome latinismo para localizar espaçotemporalmente a experiência latino-americana, não tentando constituir um substantivo, nem enlaçar relações dialéticas. O latinismo tenta criar um exemplo aproximado para a experiência narrativa da Latino-América como consequência de suas particularidades. E dentro da literatura, o latinismo poderia se formular como uma construção narrativa alternativa e dialogante, aglutinadora - não outro tipo de realismo - e ao mesmo tempo um apelo à história particular da LatinoAmérica. O termo se pode justificar em vista da análise marxista, refletida como relações de poder das sociedades europeias, ou na Europa como modelo de crítica materialista. Contrariamente, América Latina é uma construção histórica nascida no séc. XVI, ou seja, a formação do seu sociocultural expõe algumas discrepâncias, entre elas, o tempo, em analogia com o continente europeu (MIGNOLO, 2003). Esta comparação não é necessariamente uma relação dialética com a realidade europeia, no entanto, as características históricas e 
culturais (estéticas) das Américas não são feitas por semelhantes experiências de vida.

Por tal motivo, o latinismo não figura nesta investigação como definição nem conceito, mas como experiência dinâmica sociocultural, política e religiosa, a partir de várias sequências causais dos encontros de três - ou mais - mundos. Cada mundo agregou sua própria experiência, tanto a inicial, quanto a consequente, para surgir uma aglutinação menos uniforme ${ }^{11}$ do que a experiência europeia, porque, para Bolaño:

$\mathrm{Na}$ Europa somos conhecidos por nossas queixas e por nossas lágrimas de crocodilo. Latino-América é o mais parecido que há à colônia penitenciária de Kafka [...]. Nosso discurso da riqueza é o mais parecido que há com um livro barato de autoajuda. Nosso discurso da pobreza é um discurso imaginário em que só se ouvem vozes de loucos que falam de ressentimento e frustração. Odiamos os argentinos porque eles são o mais parecido que há em nossos lares aos europeus. Os argentinos nos odeiam porque somos o espelho em que se veem como o que são, isto é, latino-americanos ${ }^{12}$ (BOLAÑO, 2011, p. 97).

Nesse contexto, a literatura latino-americana, segundo Bolaño, sofre o padrão revisado da sua própria história, produto das suas guerras particulares e das sequelas que deixaram, embora uma outra conjuntura estética narrativa prevalecesse antes desse confronto psicológico citado por Bolaño: a narrativa do Boom latino-americano. O contexto do Boom procurou sua experiência particular (BURGOS, 1997), mesmo que não haja tido uma ruptura total com o sistema literário de bases ocidentais ${ }^{13}$. Nesse aspecto, a crítica literária, geral e constantemente de matriz ocidental, ressaltou as peculiaridades narrativas numa tendência que foi nomeada de realismo mágico (MENTON, 1998), cujas estéticas produziram uma literatura com certa identidade latino-americana (SHAW, 1996).

Consequentemente, não é que a obra de Bolaño funde uma visão diferente e tergiversadora da tendência do Boom, senão que sua maneira de narrar está sumamente ligada à sua crítica e às suas experiências, o que

11 Acredita-se que a experiência não é uniforme de maneira alguma, mas as histórias, em determinados e aproximados contextos espaço-temporais podem apresentar características semelhantes. Assim, antes da chegada europeia às Américas, havia semelhanças bélicas entre suas populações, mas diversificados nos seus sistemas políticos e religiosos, e expressões artísticas diversas entre ambos os contextos espaciais. As crônicas consolidam essa primeira perspectiva.

12 Tradução livre do autor desta pesquisa. Desde esta tradução, todas serão de responsabilidade do autor.

${ }^{13}$ Num trabalho posterior, que o autor desta pesquisa ainda o desenvolve, problematizamos 0 caráter independente do Boom Latino-americano, em relação ao polissistema literário ocidental. 
particularmente diferencia sua narrativa à do Boom. Ou como menciona David Viñas "a literatura do Boom não tivesse existido, não tivesse tido a dimensão que teve a não ser pela Revolução Cubana"14. Ao escrever sua crítica, Bolaño se descentra dessa revolução, mas não a abandona por completo, porque menciona suas consequências em Latino-América.

\section{Roberto Bolaño e a literatura das Américas}

Quase ao finalizar o séc. XX, exatamente desde 1998, o nome Roberto Bolaño passa a ser o centro das atenções no mundo literário de língua hispânica, com uma fortuna crítica bastante positiva. Posteriormente, já no séc. XXI, Bolaño é um dos nomes mais citados a nível mundial, mencionado e traduzido para várias línguas ${ }^{15}$, a partir de uma das editoras mais prestigiosas do mundo: Anagrama. Ironicamente ${ }^{16}$, esta conquista fazia parte da sua homenagem póstuma, em que a crítica lhe cedera um lugar no âmbito da literatura, após a sua desaparição, em julho de 2003, em pleno apogeu das suas produções. O editor de Anagrama, o espanhol Jorge Herralde, menciona que "Num encontro de escritores latino-americanos em Sevilha, foi consagrado como o melhor e mais influente romancista da sua geração, por total unanimidade" (HERRALDE, 2005, p. 21-22). Outra voz internacional, a pesquisadora, escritora e crítica Susan Sontag, a partir da obra Nocturno de Chile (2006), refere-se a Bolaño (Roberto) como "um escritor extraordinário que nenhum leitor digno de tal nome deveria perder-se, um must' (SONTAG, 2006, p. 22). Já na América Latina, a crítica chilena Patricia Espinosa (2003) e a argentina Celina Manzoni (2006) destacam solenemente o trabalho desesperado de Roberto Bolaño. Nesse aspecto, Manzoni (2006, p. 11) afirma que "Roberto Bolaño tem feito em relativamente pouco tempo a façanha que perseguiram, às vezes iludidas, as vanguardas: criar seu próprio público".

\footnotetext{
14 Disponível em: <http://www.juventudrebelde.cu/cultura/2007-02-18/el-boom-latinoamericano-dela-literatura-no-se-hubiera-podido-producir-sin-la-revolucion-cubana>. Acesso em: 12 ago. 2018. 15 No Brasil, os direitos de tradução pertencem à editora Companhia das Letras.

16 Outra ironia que vale mencionar é a ruptura que a viúva de Roberto Bolaño fez com a editora Anagrama, para fazer acordo com a editora Alfaguara, distribuída pelo grupo Amazon, numa disputa de mecenas.
} 
Dessa forma, o sucesso da produção literária de Bolaño é inegável, posto que é discutida e argumentada desde mais de uma perspectiva, como supracitado ao longo da pesquisa. No entanto, o que a torna tão especial se a crítica anterior conviveu com os autores do Boom, inclusive no seu establishment outorgado pela crítica de bases europeias? Ou seja, a dinâmica espaço-temporal descartou o antigo consagrado, na produção narrativa latino-americana, ainda com repercussão mundial, para dar passo a algo quase desconhecido? Por quê?

Num primeiro olhar, a discussão ao redor do sucesso da produção narrativa de Roberto Bolaño se coloca muito mais como uma problemática do seu modelo artístico/narrativo do que para estabelecer uma outra posição paradigmática - conservadora, na Hispano-América. Isto deriva do fato de que, mesmo não tendo recebido nem nominação a um Nobel de literatura, Bolaño recebeu o Premio Herralde de Novela, em 1998 (Espanha), e o prestigioso Prêmio Rómulo Gallegos, em 1999 (América Latina), num pouco mais de quatro anos de aparecer como escritor. Mesmo assim, a fortuna crítica veio tarde, já que, para sobreviver antes do êxito, Bolaño teve de procurar prêmios literários regionais, além de trabalhar em vários ofícios.

Por conseguinte, a crítica literária também assume um papel importante ao considerar a obra de Bolaño como uma voz narrativa diferente da do Boom ${ }^{17}$, talvez esta já em estado de desgaste pela dinâmica da literatura e que, consequentemente, sugere um ponto inicial de inflexão, a partir do seu repertório temático (CHACON, 2015). Por exemplo, as obras de Bolaño agregam um leitmotiv um tanto diverso dos seus pares contemporâneos consagrados, como Isabel Allende ou Laura Esquivel - que ainda se valem do realismo mágico - e um tanto aproximado na ironia, em autores como Augusto Monterroso. Porém, a recepção crítica sugere um repertório temático mais diverso em Bolaño, em vista do seu rápido reconhecimento, num pouco mais de meia década desde a aparição da sua primeira obra, em solo ${ }^{18}$.

Assim, a diversidade do seu repertório deriva de uma aglutinação de vários quesitos experimentais como sua leitura voraz por todo tipo de escritores,

\footnotetext{
${ }_{17}$ A jornalista Mónica Maristain declarou que Bolaño foi o escritor que liberou a América Latina do Boom. Disponível em: <http://www.telam.com.ar/notas/201511/127681-monica-maristain-robertobolano-literatura-latinoamericana.php>. Acesso em: 14 ago. 2018.

${ }^{18} \mathrm{Em} 1984$, Roberto Bolaño já tinha escrito um romance, mas "a quatro mãos", com o escritor A. García Porta.
} 
até os não canonizados. Também, trabalhou sua memória como experiência geográfica, posto que desde adolescente foi transitando o continente americano, desde Chile, seu país natal, até México, onde radicaria sua juventude e ponto de partida para Espanha. Igualmente, sua memória experimentou experiências políticas infames, desde a ditadura de Pinochet, da qual foi salvo, até atrocidades feitas por guerrilhas de esquerda, na América Central. Esses périplos são construções marcantes na poética de Bolaño, como parte de narrativas constituídas por "ficções biográficas" (HOUVENAGHEL; LOGIE, 2009, p. 149), marcas constantes do estilo do narrador como crítico (FRIEDMAN, 2002).

Posteriormente, antes da sua consagração na literatura, a obra de Bolaño conheceu a recusa de várias editoras, fato que alimentará ainda mais a sua obra, seja como narrador, seja como (auto)crítico literário. Para entender um pouco mais sobre essa discussão, a coletânea de ensaios póstumos - Entre paréntesis (2004) - é uma compilação crítica em que Bolaño provoca tensões com o cânone, enquanto assume uma postura de crítico da literatura.

Inédito no Brasil, o corpus dessa obra se constrói com algumas resenhas de livros, sobre diversos autores, pontos de vista e, como ressalta o compilador e editor do livro, o espanhol Ignacio Echevarría (In BOLAÑO, 2004, p. 7), "configura algo parecido a uma cartografia pessoal [...] uma espécie de "autobiografia" fragmentada".

Nasci em 1953, no ano em que morreu Stalin e Dylan Thomas. Em 1973 fiquei oito dias detido pelos militares golpistas do meu país e na quadra onde ficavam os presos políticos achei uma revista inglesa com uma reportagem fotográfica da casa de Dylan Thomas em Gales (BOLAÑO, 2004, p. 19)

Bolaño também impregna seus pontos de vista favoráveis sobre obras de diversos autores, como convite para leitura e apreciação de novos escritores, além de mencionar alguns já desaparecidos ou, na língua do cânone, escritores menores.

Pezoa Véliz sem dúvida é o poeta menor por excelência do Parnaso chileno e também um dos mais misteriosos [...] Porém escreveu mais de três poemas (talvez seis ou sete) bons, e um deles, "Tarde en el hospital", possivelmente pouco antes de morrer, autenticamente bom (BOLAÑO, 2004, p. 155-156). 
Geralmente, a obra está composta por críticas de caráter literário, nas quais Bolaño, além de colocar um toque biobliográfico, recomenda escritores pela impressão narrativa das suas obras, por algum critério ressaltante, como no caso do argentino Andrés Neuman:

\begin{abstract}
Entre os jovens escritores que já publicaram seu primeiro livro, Neuman quiçá seja o mais jovem de todos [...]. É o autor de um livro de poemas, Métodos de la noche [...] e de Bariloche, um excelente primeiro romance com o que foi finalista do último Premio Herralde (BOLAÑO, 2004, p. 149).
\end{abstract}

Porém, a obra Entre paréntesis é mais conhecida pelas suas críticas, enquanto Bolaño, na função de crítico "sem papas na língua", que o fez alvo de diversos comentários negativos dos seus colegas escritores, até criar-Ihe um clima hostil por parte de diversos meios literários canônicos, sobretudo o chileno.

\footnotetext{
Quer dizer: a literatura de (Isabel) Allende é ruim, mas está viva; é anêmica, como muitos latino-americanos, porém está viva. [...] Não posso dizer o mesmo da literatura de Skármeta e Teitelboim. A estes não os salva nem Deus (BOLAÑO, 2004, p. 102).
}

Igualmente, refere-se aos seus conterrâneos: José Donoso como um exagero, ao ser mencionado como o melhor romancista chileno do séc. XX (BOLAÑO, 2004, p. 100); Norberto Fuentes, não como escritor, mas como uma alma em pena (BOLAÑO, 2004, p. 160), e Diamela Eltit, da literatura canonizada contemporânea, como "uma das mais complexas que se escrevem hoje em espanhol" (BOLAÑO, 2004, p. 75).

Além desses autores chilenos reconhecidos - entre outros -, Bolaño também direciona suas críticas ao leitor que produziu a obra do poeta Pablo Neruda, evidenciando, dessa maneira, seu descontentamento com o cânone literário histórico. Igualmente, Bolaño não só fez críticas às obras do contexto literário chileno, também o fez para outros contextos, como o cânone brasileiro, com adjetivos direcionados a Nélida Piñon e a Paulo Coelho (BOLAÑO, 2004, p. 103), por exemplo; e a outros autores internacionais.

Da mesma forma, a obra critica o partidarismo político, tanto à esquerda quanto à direita por igual, pelas atrocidades feitas pelo poder (BOLAÑO, 2004, p. 201), independente da sua ideologia. Nesta última perspectiva, a pesquisadora Daniuska González, no seu livro La escritura bárbara. La narrativa de Roberto 
Bolaño (2010) ensaia sobre o efeito da destruição, da violência e do mal que aparecem na poética do escritor, como alimento da literatura na América Latina. Segundo González:

\begin{abstract}
Bolaño esquarteja sem piedade o mundo da literatura, como se 0 olhasse com um escalpelo. Introduz agulhas nas partes fracas do corpo literário: escritas médias, indivíduos às margens dos circuitos editoriais, sem reconhecimento; as figuras canônicas como vontades de poder, falsas e medíocres; inveja, fragilidade e derrota (GONZÁLEZ, 2010, p. 176).
\end{abstract}

Também a crítica e pesquisadora Celina Manzoni caracteriza a narrativa de Bolaño como uma crítica proposital ao cânone, manifestando sobre este movimento literário que:

\begin{abstract}
Como recurso de uma estética desmistificadora, o procedimento pode resultar literariamente eficaz para mudar de sentido ou pelo menos perturbar um cânone que ao desdenhar o alcance do espírito desmistificador perpetua uma retórica que se constitui na confirmação de uma linguagem que proclama inimizade (MANZONI, 2006, p. 32).
\end{abstract}

Da mesma forma, uma citação de Bolaño dá a entender a urgência de uma nova crítica literária latino-americana, no livro Entre paréntesis, que na sua última parte retoma uma entrevista feita pela revista Playboy do México, com a jornalista Mónica Maristain. Nesta, Bolaño cita o seguinte "De fato, a necessidade de uma, vamos chamá-la assim, uma nova crítica é algo que já se faz urgente em toda Latino-América" (BOLAÑO, 2004, p. 339).

Nesse sentido, a pesquisa considera o seguinte:

a. Bolaño vivenciava a literatura porque, para sua produção, a vida e arte se confundem, se condensam nela ${ }^{19}$, no seu próprio movimento e no seu próprio diálogo, que não é harmônico. Como consequência, para Bolaño, a literatura não seria o reflexo da vida, mas uma reinterpretação dela, constante, dentro da sua pureza estética ingênua e da sua insanidade mnemônica, um pacto não declarado entre a fiç̧ão e a história. Como consequência, há experiências históricas específicas que contar, na narrativa latino-americana, (con)sequências de tempo que conviveram num espaço fragmentado pelo

19 Declarações do escritor brasileiro Eduardo Sterzi. Disponível em: <http://jconline.ne10.uol.com.br/canal/cultura/literatura/noticia/2013/07/15/a-literatura-exilada-debolano-89820.php>. Acesso em: 28 jul. 2018. 
horror particular nas Américas, pelas ditaduras de direita e de esquerda, com a mesma ambivalência. As ditaduras pertencem ao poder, seja ele qual for, e daí deriva uma história estética do execrável, do inefável como experiência continental específica.

b. Logo, o materialismo histórico de Marx - ou marxismo - não fica patente no continente americano, senão como um impreciso imaginário global, uma suposição de lutas de classes, um discurso vazio da esquerda (BOLAÑO, 2004 , p. 339) num contexto geopolítico que serve como subalterno de uma realidade europeia. E nessa subalternidade está a literatura latino-americana, marcada pelo sangue da sua construção, o abjeto da sua memória, que não sabe de feudos nem de palácios, a não ser por fraca imitação. Só o poder se encaixa como eixo dessa narrativa. A experiência não acaba porque a matéria constitui constantemente pensamento e ação que, na leitura crítica de Bolaño, são formas desreguladas pela narrativa da memória. Uma das disposições do seu posicionamento crítico está baseada no delírio de grandeza da subalternidade, como algo tangível na literatura das Américas.

c. Igualmente, para a crítica do escritor, a dialética não funciona porque um escritor menor pode chegar a ser imediatamente maior, a sua fortuna crítica não depende necessariamente do cânone e este está obrigado a aderi-lo. $O$ escritor menor e a sua escrita são observadas com minúcia para alimentar o mecenas, figuras que percorrem a narrativa de Bolaño. Pelo contrário, a crítica literária marxista parte, fundamentalmente, de um escritor canonizado, de um autor já analisado e prestigiado, um best-seller, em função de certos padrões estéticos cristalizados pelo cânone. Para Bolaño, o objeto literário não vive diametralmente oposto a seu autor, senão está intrinsecamente ligado a ele, como experiência, pensamento e reconhecimento das coisas narradas, sendo a literatura um mundo desconhecido, com regras desconhecidas, uma reinvenção de uma história local que acontece em toda parte.

\section{Referências}


ADORNO, Theodor. Notas de literatura I. Tradução Jorge de Almeida. $2^{\underline{a}}$ edição. São Paulo: Editora 34, 2012.

AUERBACH, Erich. Introdução aos estudos literários. Tradução José Paulo Paes. São Paulo: Cosac Naify, 2015.

BENJAMIN, Walter. Magia e técnica, Arte e política, I. Tradução Sérgio Paulo Rouanet. 8ª edição. São Paulo: Editora Brasiliense, 2012.

BOLAÑO, Roberto. Entre paréntesis. Barcelona: Anagrama, 2004. . Nocturno de Chile. Barcelona: Anagrama, 2006.

BOURDIEU, Pierre. A distinção: crítica social do julgamento. Tradução Daniela Kern; Guilherme Teixeira. 2a edição. Porto Alegre: Zouk, 2015.

. O Poder Simbólico. Tradução Fernando Tomaz. Rio de Janeiro: Bertrand Brasil, 2010.

BURGOS, Fernando. El Cuento Hispanoamericano en el Siglo XX, I. Madrid: Castalia S.A. 1997.

CHACON, Juan. A função da produção de Roberto Bolaño na canonização de novos modelos para a narrativa hispano-americana no final do séc. XX. 2015. Dissertação (Mestrado em Estudos Literários pelo Programa de Pós Graduação em Letras e Lingüística) - Faculdade de Letras, Universidade Federal de Goiás, Goiânia.

ESPINOSA, Patricia. Territorios en fuga: Estudios críticos sobre la obra de Roberto Bolaño. Andalucía: Editorial Frasis, 2003.

EVEN-ZOHAR, Itamar. Teoría dos Polissistemas. Tradução Luiz Fernando Marozo; Carlos Rizzon et all. Rio Grande do Sul: 2013. Disponível em: <http://www.seer.ufrgs.br/translatio/article/viewFile/42899/27134>. Acesso em: 14 jul. 2018.

FRIEDMAN, Norman. O Ponto de Vista na Ficção: o Desenvolvimento de um Conceito Crítico. Revista USP. São Paulo, n. 53, 2002.

GONZÁLEZ, Daniuska. La Escritura Bárbara. La Narrativa de Roberto Bolaño. Lima: Fondo Editorial Cultura Peruana, 2010.

HERRALDE, Jorge. Para Roberto Bolaño. Acantilado, 2005. Disponível em: <https://books.google.com.br/books?id=4wzKNUBicegC\&pg=PA15\&hl=pt$B R \&$ source=gbs_toc_r\&cad=3\#v=onepage\&q\&f=falsel>. Acesso em: 20 jul. 2018. HOUVENAGHEL, Eugenia ; LOGIE, Ilse. Alianzas entre historia y ficción: homenaje a Patrick Collard. Ginebra: Droz S. A., 2009. 
MANZONI, Celina. Roberto Bolaño: la escritura como tauromaquia. Buenos Aires: Corregidor, 2006.

MARX, Karl. O capital. Tradução Gabriel Deville. 3ª edição. São Paulo: Editora Edipro, 2008.

MENTON, Seymour. Historia Verdadera del Realismo Mágico. México D.F.: Fondo de Cultura Económica, 1998.

MIGNOLO, Walter. Histórias locais, projetos globais. Tradução Solange Ribeiro de Oliveira. Belo Horizonte: Editora UFMG, 2003.

SHAW, Donald. La Nueva Narrativa Hispanoamericana. 5. ed. Madrid: Cátedra, 1996.

WILLIAMS, Raymond. Marxismo e Literatura. Rio de Janeiro: Zahar, 1979.

ŽIŽEK, Slavoj. Um mapa da ideologia. Tradução Vera Ribeiro. Rio de Janeiro: Editora Contraponto, 2013.

Recebido em 03/08/2018.

Aceito em 14/10/2018. 